\title{
Degradation of Dipalmitoyl Phosphatidylcholine by Isolated Rat Granular Pneumocytes and Reutilization for Surfactant Synthesis
}

\author{
Avinash Chander, Jayne Reicherter, and Aron B. Fisher \\ Institute for Environmental Medicine, University of Pennsylvania School of Medicine, Philadelphia, Pennsylvania 19104-6068
}

\begin{abstract}
We investigated metabolic utilization of exogenous (modelled after lung surfactant) phospholipids by granular pneumocytes in primary culture. Cells were incubated for 21,65 , and $140 \mathrm{~min}$ with $\left[{ }^{3} \mathrm{H}\right.$-methyl]dipalmitoylphosphatidylcholine (DPPC) containing liposomes prepared from synthetic lipids. Radioactivity in cellular phosphatidylcholine (PC) declined steadily to $50 \%$ of the total trypsin-resistant cell-associated radioactivity. The proportion of radioactivity increased with time in cytidine-5'-diphosphate-choline and phosphorylcholine, which suggested reutilization of choline for PC synthesis. Cells incubated with liposomes for $2 \mathrm{~h}$ revealed that of the total cell-associated radioactivity, $7 \%$ was in lamellar bodies and $10 \%$ in the microsomal fraction. The lipid-associated radioactivity was $24 \%$ in "soluble," 96\% in lamellar bodies, and 92\% in the microsomal fraction. Percent of total PC label recovered in disaturated PC of microsomal fractions decreased (slope $=-5.27 \% / \mathrm{h}$ ) with time of incubation $(r=0.67)$. Incubation of cells with liposomes containing $\left\{{ }^{3} \mathrm{H}\right.$-methyl $]$ choline $-\left[{ }^{14} \mathrm{C}\right]$ palmitoyl $\}$ DPPC led to altered isotope ratios in both lamellar bodies and microsomes. These observations indicate that granular pneumocytes degrade exogenous PC and resynthesize PC from degradation products.
\end{abstract}

\section{Introduction}

The surface tension lowering properties of lung surfactant are ascribed to the presence of dipalmitoylphosphatidylcholine (DPPC) ${ }^{1}$ (1). This phospholipid accounts for almost half of the phospholipids recovered in the lung surfactant (2). There is strong evidence that this and other components of lung surfactant are synthesized in the type II epithelial cells (3) and stored in their lamellar bodies (4) before secretion onto the alveolar surface (57). The extracellular phospholipids are removed from the alveoli by several possible pathways. One of these pathways, involving ingestion and degradation of phospholipids by macrophages, has been shown to have a relatively minor importance in clearance of surfactant phospholipids, as evidenced by studies involving pulse-labeling kinetics (5) and in vivo instillation of radio-labeled

This paper was presented in part at the Federation of American Societies for Experimental Biology meeting held in April, 1985 in Anaheim, CA. 1986

Received for publication 26 June 1986 and in revised form 30 October

1. Abbreviations used in this paper: CDP-choline, cytidine-5'-diphosphate-choline; DPPC, dipalmitoylphosphatidylcholine; DSPC, disaturated PC; MEM, minimum essential medium; PC, phosphatidylcholine; PG, phosphatidylglycerol.

J. Clin. Invest.

(C) The American Society for Clinical Investigation, Inc.

0021-9738/87/04/1133/06 \$1.00

Volume 79, April 1987, 1133-1138 biosynthesized surfactant $(8,9)$. Another pathway of surfactant clearance by lung tissue has been elucidated in recent years. In vivo studies on instillation of biosynthesized surfactant (9-11) or liposomes prepared from synthetic lipids $(11,12)$ have suggested involvement of granular pneumocytes in this process. Using these cells in primary culture, we have previously shown that they internalize exogenous phospholipids and that this uptake is dependent upon concentration of phospholipids, the time and temperature of incubation, and can be modulated by metabolic inhibitors (13). In this report we extend our investigation to localize the phosphatidylcholine (PC) radioactivity in subcellular fractions and provide evidence for resynthesis of PC from degradation products.

\section{Methods}

Preparation of liposomes. Liposomes were prepared from lipid mixtures containing DPPC/egg PC/phosphatidylglycerol (PG) and cholesterol (10:5:2:3, $\mathrm{mol} / \mathrm{mol})$. Trace radiolabeled lipids were added to the lipid mixture in chloroform solution. The lipid mixtures were then dried under nitrogen, resuspended in $1 \mathrm{ml}$ of saline, and liposomes prepared by sonication as described previously (13). Sonication was performed using a probe sonicator (sonic dismembrator, model 150; Artek Systems Corp., Farmingdale, NY) set at $40 \%$ of maximum output. Trace radiolabeled lipids were $\left[{ }^{3} \mathrm{H}-\right.$ methyl $]$ choline DPPC, $\left[1-{ }^{14} \mathrm{C}\right]$ palmitoyl DPPC, or [1${ }^{14} \mathrm{C}$ ]palmitoyl-2-oleoyl PC.

Preparation of $1-\left[{ }^{14} \mathrm{C}\right]$ palmitoyl-2-oleoyl PC. $1-\left[{ }^{14} \mathrm{C}\right]$ palmitoyl lyso $\mathrm{PC}$ was dissolved in chloroform and dried under nitrogen. The dried lipid was suspended in Tris- $\mathrm{HCl}$ buffer ( $\mathrm{pH}$ 7.4) using a bath sonicator and $0.1 \mathrm{mM}$ oleoyl-coenzyme $A$ and $25 \mathrm{mg}$ rat liver microsomal protein (for acyl transferase activity) were added to this suspension. The mixture (final volume $2.0 \mathrm{ml}$ ) was incubated at $37^{\circ} \mathrm{C}$ for $30 \mathrm{~min}$. The incubation was terminated by addition of $5 \mathrm{ml}$ of chloroform/methanol (1:2 vol/ vol). Lipids were extracted (14), and PC was separated by thin-layer chromatography. Almost $70 \%$ of lyso PC was converted to PC. Only $10 \%$ of recovered $\mathrm{PC}$ radioactivity was in the disaturated species.

Cell isolation. Specific pathogen-free adult male Sprague-Dawley rats (Charles River Breeding Laboratories, Wilmington, MA) weighing $200 \mathrm{~g}$ were used for isolation of alveolar epithelial type II cells (15). Rats were anesthetized with $50 \mathrm{mg} / \mathrm{kg}$ sodium pentobarbital and lungs were cleared of blood by a brief period of perfusion with minimum essential medium (MEM). Lungs were dissected free of trachea and large bronchi, and minced. Alveolar epithelial type II cells were isolated by tryptic digestion and differential adherence as described previously (15). Type II cells for all experiments were used after $24 \mathrm{~h}$ in primary culture. Routine examination of cells at the end of $24 \mathrm{~h}$ showed $>90 \%$ purity of type II cells and $>93 \%$ excluded erythrosin $B$.

Incubation of cells with liposomes. Cells adherent to plastic after 24 $h$ in culture were washed with serum-free MEM three times to remove any residual serum. The cells were then incubated in serum-free MEM $(6 \mathrm{ml})$ with liposomes added to give a final concentration of $0.2 \mathrm{mM}$ PC. Incubation with liposomes was carried out for some experiments in the presence of $100 \mu \mathrm{M}$ quinacrine, $100 \mu \mathrm{M}$ chloroquine, $50 \mu \mathrm{M}$ methylamine, $10 \mathrm{mM} \mathrm{NH}_{4} \mathrm{Cl}$, or in choline-free MEM. The incubation was terminated at varying times by removing the incubation medium and washing the cells five times with ice-cold MEM. The flasks were treated with $5 \mathrm{mM}$ EDTA to remove macrophages and type II cells were harvested 
using a single $10-\mathrm{min}$ incubation with $0.25 \%$ trypsin. The time elasped between termination of incubation with liposomes and harvesting of cells was $\sim 20 \mathrm{~min}$. The cells were pelleted, washed once with saline, sonicated in saline, and aliquots were removed for extraction of lipids (14) and determinations of proteins and cell-associated radioactivity.

Isolation of subcellular fractions. For isolation of lamellar bodies, $\sim 2.5 \times 10^{7}$ cells were sonicated in $1 \mathrm{ml}$ of $1 \mathrm{M}$ sucrose giving two bursts of $15 \mathrm{~s}$ each and $5 \mathrm{~s}$ apart. Lamellar bodies from this homogenate were isolated by upward flotation on a discontinuous sucrose density gradient (16). The lamellar bodies band at the interface between 0.42 and $0.47 \mathrm{M}$, and remaining particulate material was recovered in the pellet. This interface was diluted to $0.2 \mathrm{M}$ sucrose and lamellar bodies recovered by centrifugation at $20,000 \mathrm{~g}$ for $15 \mathrm{~min}$. We have shown previously that the lamellar bodies are recovered in the pellet with minimal succinate dehydrogenase or NADPH-cytochrome $c$ reductase activity (16)

For preparation of a microsomal fraction, $2.5 \times 10^{7}$ cells were sonicated in $2.0 \mathrm{ml}$ of $10 \mathrm{mM}$ Tris- $0.15 \mathrm{M} \mathrm{NaCl}-0.32 \mathrm{M}$ sucrose, and centrifuged at $7,700 \mathrm{~g}$ for $20 \mathrm{~min}$. The supernatant placed over $0.8 \mathrm{M}$ sucrose was spun at $80,000 \mathrm{~g}$ for $3 \mathrm{~h}$. The soluble fraction was isolated in 0.32 $\mathrm{M}$ sucrose and the microsomal fraction was recovered in the pellet (17). We have shown previously that the microsomal fraction showed 2.5 fold enrichment over the homogenate in rotenone-insensitive NADPHcytochrome $c$ reductase activity and $<10 \%$ contamination with succinate dehydrogenase activity (18).

Analytical techniques. Phospholipids were assayed by determination of inorganic phosphorous as described previously (19). Phospholipids were separated on thin-layer chromatography (20), visualized by brief exposure of developed plates to $I_{2}$ vapors, and identified by co-chromatography of authentic standards. For isolation of PC, the spots comigrating with authentic PC were scraped and eluted with $5 \mathrm{ml}$ of chloroform/methanol (vol/vol, 1:2) and then twice with $5 \mathrm{ml}$ of methanol. The recovery by this method exceeded $85 \%$. Disaturated PC (DSPC) was isolated by osmication of lipid extracts and chromatography on neutral alumina columns (21). Recovery, which was assessed by processing a known amount of DPPC radioactivity through osmication and columns, exceeded $90 \%$.

Water soluble choline-containing metabolites were isolated from the "upper" (aqueous) layer from the lipid extract which was evaporated to dryness under nitrogen, redissolved in $0.2 \mathrm{ml}$ of water, and separated by thin-layer chromatography on silica gel $G$ plates developed in methanol/ $0.5 \% \mathrm{NaCl} / \mathrm{NH}_{4} \mathrm{OH}(50: 50: 1, \mathrm{vol} / \mathrm{vol})(22)$. Authentic standards of cytidine-5'-diphosphate-choline (CDP-choline), phosphorylcholine, glycerophosphorylcholine, and betaine were co-chromatographed. CDPcholine was visualized by ultraviolet light and others by brief exposure to $I_{2}$ vapors.

To confirm that the radioactivity co-migrating with CDP-choline was in the choline moiety, the area of gel corresponding to authentic CDP-choline was scraped into tubes and eluted by three overnight extractions with $2 \mathrm{ml}$ of $80 \%$ ethanol. Elution of authentic $\left[{ }^{14} \mathrm{C}\right] \mathrm{CDP}$-choline was $>95 \%$ by this procedure. The eluted samples were dried under nitrogen, resuspended in $0.5 \mathrm{M}$ Tris buffer ( $\mathrm{pH} 9.5$ ), and hydrolyzed using $10 \mathrm{U}$ alkaline phosphatase and $1 \mathrm{U}$ phosphodiesterase at $37^{\circ} \mathrm{C}$ for $7 \mathrm{~h}$. The reaction was terminated by addition of $5 \mu l$ of $12 \%$ perchloric acid. The mixture was neutralized with $20 \mu \mathrm{l}$ of $6 \mathrm{M} \mathrm{K}_{2} \mathrm{CO}_{3}$. Preliminary experiments with authentic $\left[{ }^{14} \mathrm{C}\right] \mathrm{CDP}$-choline showed $>95 \%$ conversion. The hydrolysis products were then re-chromatographed on thin-layer chromatography plates that were developed for water soluble choline metabolites as described above. The choline-containing spots were scraped and radioactivity was measured in samples and in authentic $\left[{ }^{14} \mathrm{C}\right] \mathrm{CDP}$ choline standards. All radioactivity was recovered in the spot co-migrating with choline. Spots co-migrating with authentic glycerophosphorylcholine were eluted, dried, and subjected to acid hydrolysis with $1 \mathrm{M} \mathrm{HCl}$ at $100^{\circ} \mathrm{C}$ for $30 \mathrm{~min}(23)$ and the hydrolysate rechromatographed. All radioactivity in the hydrolysate co-migrated with choline.

Proteins were determined on aliquots of sonicated cells by protein dye binding reagent (Bio-Rad Laboratories, Richmond, CA) according to Bradford (24). Radioactivities were measured by liquid scintillation counting using $1 \mathrm{ml}$ water in $10 \mathrm{ml}$ Liquiscint (National Diagnostics, Inc., Manville, $\mathrm{NJ}$ ).

Materials. $\left[{ }^{14} \mathrm{C}\right] \mathrm{CDP}$-choline, $\left[1-{ }^{14} \mathrm{C}\right]$ palmitoylglycerophosphorylcholine, $\left[{ }^{3} \mathrm{H}-\right.$ methyl $] \mathrm{DPPC}$, and $\left[{ }^{14} \mathrm{C}\right.$-palmitoyl]DPPC were obtained from New England Nuclear, Boston, MA. DPPC, egg PC, phosphatidylglycerol (PG), chloroquine diphosphate, quinacrine hydrochloride, alkaline phosphatase, and phosphodiesterase were obtained from Sigma Chemical Co., St. Louis, MO. Authentic lipid standards were obtained from Supelco, Inc., Bellefonte, PA.

Statistical analysis. Results were evaluated for statistical significance by Student's $t$ test for unpaired data (25). The level of significance was taken as $P<0.05$.

\section{Results}

Incubation of granular pneumocytes with $\left[{ }^{3} \mathrm{H}\right] \mathrm{DPPC}-\mathrm{containing}$ vesicles showed that the trypsin-resistant radioactivity associated with cells increased nonlinearly with time of incubation, and by $4 \mathrm{~h}$ the cells had taken up $\sim 3 \mathrm{nmol} \mathrm{PC} / \mathrm{mg}$ cell protein (Fig. 1). This represents $\sim 0.5-1.0 \%$ of total radioactivity in the flask. Since the cells were trypsinized before analysis we assume this cell-associated radioactivity represents phospholipid internalized by the granular pneumocytes (16). The incubation medium was checked for extracellular degradation of $\left[{ }^{3} \mathrm{H}\right] \mathrm{DPPC}$ and the radioactivity partitioned into lipid soluble and water soluble choline-containing products. The radioactivity in the water soluble compartment was $<0.3-0.4 \%$.

The total trypsin-resistant cell-associated radioactivity was analyzed for choline-containing metabolites after incubation of cells with vesicles for different times. The minimum time of incubation was $1 \mathrm{~min}$. However, this was designated as $21 \mathrm{~min}$ since further incubation of $20 \mathrm{~min}$ was necessary to remove the cells from attachment to the plastic culture flask. Similarly, cells incubated for $45 \mathrm{~min}$ with vesicles were designated as $65 \mathrm{~min}$ and those for $120 \mathrm{~min}$ were designated as $140 \mathrm{~min}$. The radioactivity in PC decreased with time of incubation from $100 \%$ at zero time to $50.1 \%$ at $140 \mathrm{~min}$ (Fig. 2). At the same time, the radioactivity in the lysophosphatidylcholine fraction increased to $4.4 \%$ at $21 \mathrm{~min}$ and then decreased to $1.2 \%$ at $140 \mathrm{~min}$ (Fig. $3 \mathrm{~A}$ ). The aqueous soluble choline-containing metabolites were further separated and radioactivity in each metabolite was expressed as percent of total cell-associated dpm. The major product was glycerophosphorylcholine, which presumably results from degradation of PC by the combined action of phospholipase $A$ and lysophospholipase. The radioactivity in this fraction increased with time to $13 \%$ by 140 min (Fig. 3 B). Choline and phosphorylcholine, possible additional degradation products of $\mathrm{PC}$, and CDP-choline, an intermediate in PC biosynthesis from

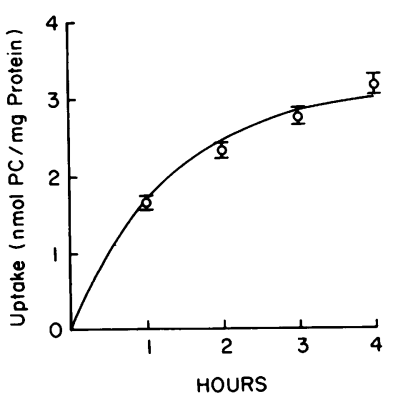

Figure 1. Uptake of liposomal PC by rat granular pneumocytes in primary culture. Isolated cells after 24-h primary culture were incubated with $\left[{ }^{3} \mathrm{H}-m e t h y l\right] \mathrm{DPPC}$ in liposomes prepared from DPPC/egg PC/PG and cholesterol (50:25:10: $15 \mathrm{~mol} / \mathrm{mol}$ ) mixtures at $\mathrm{PC}$ concentrations of $200 \mu \mathrm{M}$ in serumfree medium. Cells were harvested at indicated times and trypsin-resistant cell-associated radioactivity quantitated as described in the text. Results are mean \pm SE of six observations and are expressed as nanomoles PC per milligram cell protein. 


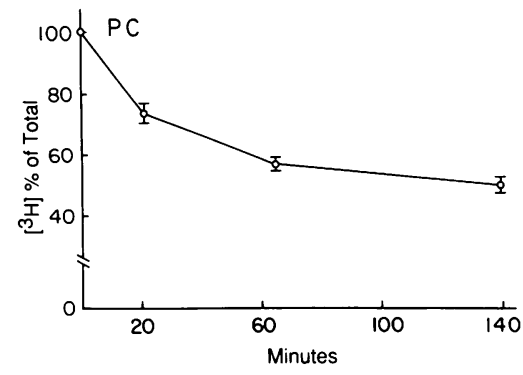

Figure 2. Fate of cell-associated PC. Cells were incubated with $\left[\left({ }^{3} \mathrm{H}-\right.\right.$ methyl)choline]DPPC containing liposomes prepared from lipid mixtures of composition as described in the legend to Fig. 1. Incubations were carried out for 1,45 , and $120 \mathrm{~min}$ and designated as 21,65 , and $140 \mathrm{~min}$ to include the 20 -min period required for harvesting the cells. Results are mean $\pm \mathrm{SE}$ of four experiments and are expressed as percent of trypsin-resistant cell-associated radioactivity.

choline, also showed increasing percent radioactivity with time (Fig. 3, $C-E$ ). We did not detect any radioactivity in betaine, which suggested little oxidation of choline by these cells. To investigate if the loss, of label from PC was a result of base exchange reaction, we incubated cells with ${ }^{3} \mathrm{H}$-choline-labeled DPPC liposomes in choline-free MEM (the control MEM contained $7 \mu \mathrm{M}$ choline). Omission of choline from the medium did not change the proportion of label remaining in cellular PC ( 36 vs. $38 \%$ in controls, mean of two separate experiments) at the end of $2 \mathrm{~h}$. Addition of basic amines did not significantly alter degradation of PC in the cells (Table I).

Investigation into subcellular localization of internalized radioactivity after $2 \mathrm{~h}$ incubation revealed that $\sim 34 \%$ of radioactivity from DPPC was recovered in the soluble fraction (Table II). The particulate fractions (microsomes and lamellar bodies) accounted for $17 \%$ of radioactivity (Table II). In two experiments, lamellar bodies were isolated from cells that had been incubated with liposomes for $10 \mathrm{~min}$. Only 3 and $4 \%$ of total radioactivity was recovered in the lamellar body fraction. Analysis of distribution of radioactivity on the gradient used to prepare the lamellar body fraction from cells after $2 \mathrm{~h}$ incubation showed that 12 and $13 \%$ of the total $(n=2)$ was recovered at the interface at $0.45 \mathrm{M}$ sucrose and that $\sim 10 \%$ was present with the pellet (data not shown). However, when liposomes were added to cell homogenates and this mixture centrifuged on the gradient used
Table I. Effect of Basic Amines on Intracellular Degradation of DPPC

\begin{tabular}{lll}
\hline Addition & No. & dpm in $\mathrm{PC}^{*}$ \\
\hline & & $\%$ \\
None & 2 & $51.6 \pm 0.1$ \\
Chloroquine $(0.1 \mathrm{~mm})$ & 2 & $54.2 \pm 2.3$ \\
Methylamine $(0.05 \mathrm{mM})$ & 2 & $55.2 \pm 1.4$ \\
Quinacrine $(0.1 \mathrm{mM})$ & 1 & 55.7 \\
$\mathrm{NH}_{4} \mathrm{Cl}(10 \mathrm{mM})$ & 2 & $55.6 \pm 1.0$ \\
& & \\
\hline
\end{tabular}

Cells were incubated for $2 \mathrm{~h}$ with $0.2 \mathrm{mM}$ liposomal PC in the absence or presence of basic amines at indicated concentrations. At the end of incubations, cells were washed extensively, trypsinized, extracted, and analyzed for lipids. Results are mean \pm range.

* Percent of total cell-associated dpm.

for lamellar body isolation, the interface at $0.45 \mathrm{M}$ sucrose had 3 and $4 \%$ of radioactivity $(n=2)$ and the pellet contained only $0.8 \%$ of the total radioactivity. A large percentage of label was recovered in the soluble fraction. Thus, these control studies show a clearly different distribution pattern for free liposomes than that for the organelles isolated from cells after incubation with liposomes.

Both lamellar bodies and microsomes isolated from cells after incubation with liposomes showed that most of the radioactivity was present in the lipid fraction. On the other hand, the proportion of lipid-associated radioactivity in the soluble fraction was significantly less (Table II). Lamellar bodies showed almost all of the radioactivity present as DSPC, while microsomal fraction and cell homogenate contained $40-50 \%$ in DSPC (Table II). In one experiment, cells were incubated with lipid vesicles for various times up to $2 \mathrm{~h}$, microsomal fraction isolated, and label in both PC and DSPC analyzed. Label in DSPC, expressed as percent of that in PC, decreased steadily from $43 \%$ (at 21 $\mathrm{min}$ ) to $29 \%$ at $140 \mathrm{~min}$ (Fig. 4). These results provide evidence for metabolic utilization of internalized lipids. This finding suggests synthesis of unsaturated PC to account for presence of radioactivity in the unsaturated $\mathrm{PC}$ of microsomal fraction.
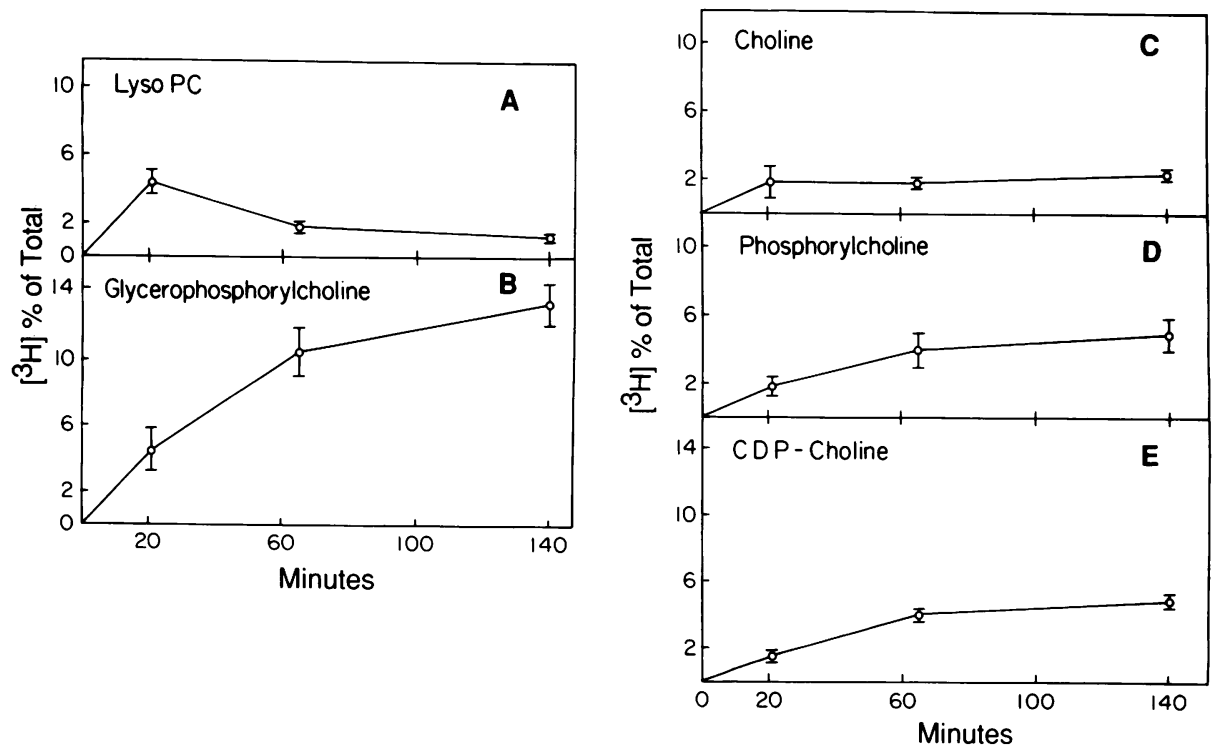

Figure 3. $\left[{ }^{3} \mathrm{H}-\right.$ methyl $]$ Choline metabolites of cell-associated DPPC. Experimental conditions were the same as described in the legend to Fig. 2. Results are mean $\pm \mathrm{SE}$ of four experiments and are expressed as percent of trypsin-resistant cell-associated radioactivity. 
Table II. Distribution of DPPC Radioactivity in Subcellular Fractions of Granular Pneumocytes at $2 h$

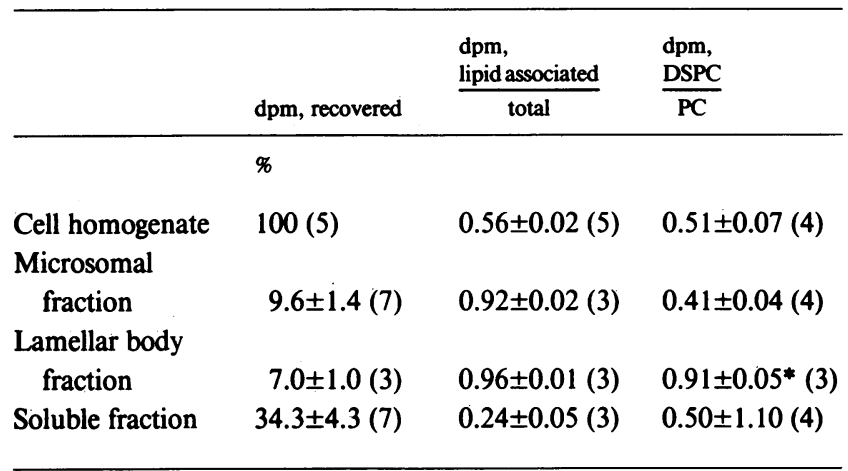

Results are mean $\pm \mathrm{SE}$ of the number of experiments (parentheses). Cells adherent to plastic were incubated with $0.2 \mathrm{mM}$ liposomal PC with tracer $\left[{ }^{3} \mathrm{H}\right] \mathrm{DPPC}$ for $2 \mathrm{~h}$, then trypsinized, and disrupted by sonication. Subcellular fractions were isolated and analyzed as given in the text. Total cell-associated radioactivity was $\sim 5 \times 10^{4} \mathrm{dpm}$.

* $P<0.01$ vs. microsomal fraction.

Since the presence of radioactivity in CDP-choline could arise from utilization of degradation products for biosynthesis, we investigated the fate of doubly labeled DPPC in the microsomal and the lamellar body fraction. An alteration in the ${ }^{3} \mathrm{H} /{ }^{14} \mathrm{C}$-ratio in $\mathrm{PC}$ was taken as an index of PC degradation and resynthesis. While the initial isotope ratios in these four experiments varied between 13-16, the isotope ratio in both lamellar bodies and microsomal fractions decreased considerably (Table III), which provided further evidence for remodelling of the internalized PC.

We next addressed the possibility of uptake and utilization of monoenoic PC using liposomes containing biosynthesized 1$\left[{ }^{14} \mathrm{C}\right]$ palmitoyl-2-oleoyl-glycerophosphorylcholine. After $2 \mathrm{~h}$ of incubation the lamellar bodies and the microsomal fractions (one experiment for each) were isolated and analyzed for radioactivity in the PC and DPPC fractions. While $10.0 \%$ of lamellar body PC radioactivity was present in DPPC, similar to that in the liposomes $(9.6 \%)$, the microsomal fraction contained almost $24.7 \%$ of the PC radioactivity in the DPPC fraction.

\section{Discussion}

This is the first report characterizing subcellular localization and metabolic utilization of internalized surfactant phospholipids

Table III. Reutilization of Exogenous DPPC by Granular Pneumocytes

\begin{tabular}{llll}
\hline & \multicolumn{3}{l}{${ }^{3} \mathrm{H} /{ }^{14} \mathrm{C}$ ratio in $\mathrm{PC}$} \\
\cline { 2 - 4 } Experiment & Liposomes & $\begin{array}{l}\text { Lamellar body } \\
\text { fraction }\end{array}$ & $\begin{array}{l}\text { Microsomal } \\
\text { fraction }\end{array}$ \\
\hline 1 & 13.5 & - & 7.6 \\
2 & 15.1 & - & 8.6 \\
3 & 15.9 & 7.5 & - \\
4 & 13.7 & 8.5 & - \\
\hline
\end{tabular}

Cells were incubated for $2 \mathrm{~h}$ with $0.2 \mathrm{mM}$ liposomal PC plus DPPC labeled with $\left[{ }^{3} \mathrm{H}-m e t h y l\right]$ choline and $\left[1-{ }^{14} \mathrm{C}\right]$ palmitate. Cells were trypsinized and subcellular fractions were isolated and analyzed as described in the text.

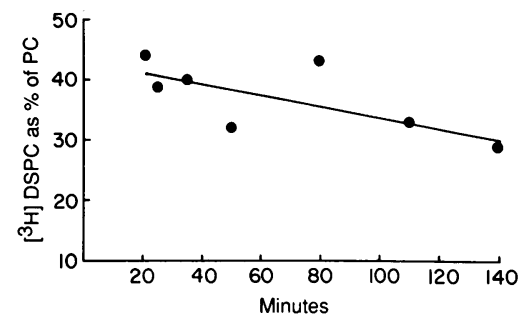

Figure 4. Microsomal DSPC radioactivity as a function of time of incubation of cells with liposomes. Rat granular pneumocytes in primary culture were incubated for indicated times with lipid vesicles of composition and label as de-

scribed in Fig. 1. Microsomal fractions were isolated and analyzed for distribution of ${ }^{3} \mathrm{H}$ in PC and DSPC. Label in DSPC is expressed as percent of that in PC. Total dpm in PC ranged from $2.6 \times 10^{3}$ to 10.1 $\times 10^{3}$. Correlation coefficient calculated using linear regression analysis for two variables (25) was 0.69 with a slope of $-5.22 \% / \mathrm{h}$.

by granular pneumocytes in primary culture. This model enables us to evaluate participation of compartments other than lamellar bodies in metabolism of internalized phospholipids.

In this report we have confirmed our previous observations on uptake and degradation of exogenous liposomal PC by granular pneumocytes (13). Trypsin-resistant cell-associated radioactivity increased nonlinearly approaching a plateau, but did not reach maximum during $4 \mathrm{~h}$ of incubation. Radioactivity in cell-associated PC decreased with time during the 140-min incubation. Cellular lyso PC initially increased, which suggested that DPPC was degraded by the action of phospholipase $A$ and that lyso PC is an initial product of breakdown of exogenous PC. During the later stages of incubation lyso PC decreased, while there was a continuous increase in glycerophosphorylcholine, which suggested further hydrolysis of lyso PC by lysophospholipase. There was no evidence of extracellular degradation of PC, since analysis of the incubation medium showed insignificant $(0.5 \%)$ amounts of radioactivity in the choline-containing water soluble products.

It is unlikely that loss of label from PC could have resulted from simple base-exchange reaction of $\left[{ }^{3} \mathrm{H}\right]$ choline of $\mathrm{PC}$ with that of intracellular choline. First, we had previously reported (13) degradation of DPPC labeled in the fatty acyl moiety comparable to the present results. Second, incubation of cells with liposomes in MEM without $7 \mu \mathrm{M}$ choline did not alter loss of label from PC, though one would expect a smaller choline pool in the cells and lower exchange reaction. Third, we did not observe progressive increase of choline label in the cells. Fourth, base-exchange reaction could not be detected in lung microsomes by other investigators (26). Finally, base exchange for PC synthesis could not be demonstrated in liver, during in vivo labeling studies (27), which suggested that it is an in vitro phenomenon.

Our attempts to modulate degradation of internalized PC by influencing the acidic compartments in the cells were not successful. We have used a group of basic compounds that are membrane permeable in undissociated form and impermeable in the protonated form (28). This protonation presumably takes place in an acidic compartment, where these compounds may alter enzyme activities either by raising the intracompartmental pH or by directly influencing the enzyme activities. Our results with these compounds do not suggest any significant degradation of internalized PC in the acidic compartments. A previous study using a fluorescent PC analogue with cultured Chinese hamster fibroblasts indicated that degradation of the phospholipid occurred at the plasma membrane, while additional lipid was transferred to the Golgi by endocytosis (29). The inability of 
basic amines to inhibit PC degradation in the present study is compatible with this previous report.

Subcellular distribution of internalized PC. Subsequent to cellular uptake, a significant part of the radioactivity was coisolated with the "soluble fraction" of cells. We did not assess recoveries of different subcellular fractions and, therefore, cannot quantitate distribution of lipid label in the intact cells. Only $24 \%$ of the total radioactivity in this fraction was lipid soluble, which suggested extensive breakdown of PC. In the microsomal and the lamellar body fractions, almost all the radioactivity was present in the lipid soluble fraction. We cannot exclude the possibility that disruption of cells by sonication could result in breakdown of some of the lamellar bodies, which would result in the release of lamellar body lipids. In such an event, these lipids will co-isolate with the soluble fraction because of their low density. However, the microsomal fraction is unlikely to contain any contaminating lamellar bodies lipids since it was sedimented through $0.8 \mathrm{M}$ sucrose. Also, this fraction was relatively pure as it did not exhibit any contamination with succinate dehydrogenase, a mitochondrial marker. We have previously isolated lamellar bodies by the method used here and characterized them using biochemical and ultrastructural techniques (16). This lamellar body-rich fraction did not show any detectable contamination with microsomal NADPH-cytochrome $c$ reductase or succinate dehydrogenase, which supports the conclusion that the data obtained with this fraction did not result from contamination with other organelles. For control experiments, radiolabeled liposomes were added to cell homogenates and gradient centrifugation for isolation of lamellar bodies was carried out. There was no preferential binding of PC to either the lamellar bodies (10) or other particulate fractions. This would suggest targeting of internalized phospholipids to various subcellular organelles.

Resynthesis of PC. Both choline and choline phosphate could result from degradation of $\mathrm{PC}$ by phospholipase activity or from hydrolysis of glycerophosphorylcholine. It has been suggested that glycerophosphorylcholine may be an intermediate in biosynthesis of PC in muscle (28). Further, choline phosphate could also result from biosynthesis by phosphorylation of choline by choline kinase. Whatever the pathway of choline phosphate formation, this compound appears to be directed towards CDPcholine formation at a steady rate, since the changes in percent radioactivity in these two fractions followed a similar course. The radioactivity in the CDP-choline fraction could result only from biosynthetic activity and could not result directly from degradation of DPPC. Formation of this metabolite from reverse reaction of choline phosphotransferase (30) is unlikely, since this pathway shows very low affinity for DPPC (31). This supports our earlier conclusions for reutilization of components based on appearance of radioactivity derived from DPPC fatty acid in the PG fraction (13).

Further evidence for utilization of degradation products for biosynthesis is provided from the observation that only $41 \%$ of microsomal PC radioactivity was recovered in DSPC (Table II). Since the initial radioactivity was all in DPPC, all of the PC radioactivity should have been recovered in the DPPC fraction if no resynthesis had occurred. Time course experiments with analysis of microsomal fraction revealed that label decreased in DSPC and increased in unsaturated PC. These results would suggest that (a) DPPC from liposomes was degraded in endoplasmic reticulum and/or transported out, or $(b)$ newly synthesized PC in this compartment was predominately unsaturated.
However, it is not possible to derive reliable half-life estimate of this phenomenon, since sufficient number of experiments (due to small amounts of materials available) could not be carried out.

Additional evidence for resynthesis of $\mathrm{PC}$ was obtained from experiments utilizing doubly labeled DPPC liposomes. Simple degradation of DPPC should not change the isotope ratio in PC of any subcellular compartment. However, resynthesis of PC from fatty acids and choline would, provided the turnover of these two substrates is different, change the isotope ratio. Our observations on altered isotope ratios in lamellar bodies and microsomes suggest resynthesis of PC in the cells, although the extent of this synthetic activity can not be ascertained. Since the radioactivity in choline decreased relative to that in fatty acids, it is unlikely that lyso PC formed during degradation was significantly reesterified to $\mathrm{PC}$. If there was appreciable deacylationreacylation of DPPC, one would observe increased ${ }^{3} \mathrm{H} /{ }^{14} \mathrm{C}$-ratio because of dilution of fatty acid label with the endogenous pool. These results also suggest that relative to choline, fatty acids enter a smaller or more rapidly turning over pool and would be compatible with different biological half-lives for palmitate and choline moiety of surfactant DPPC (4).

Use of unsaturated PC labeled with palmitate provided information on utilization of this molecular species of PC for deacylation-reacylation process as well as for preferential intraorganelle transfer. Our results on lamellar body fractionation do not support a preferential transfer of either the unsaturated or saturated PC to these organelles. Further, there was no evidence of deacylation-reacylation of internalized PC. Both of these processes would have resulted in altered radioactivities in DSPC of the isolated lamellar body fraction. It is still possible that some of the internalized PC is degraded in the lamellar bodies and the products transferred to another compartment. If such degradation occurred, it was not specific for either of the molecular species of PC. On the other hand, an increased percentage of radioactivity in DSPC of microsomes raises the possibility that some deacylation-reacylation reaction occurred in these organelles. However, further studies are required to distinguish such remodelling from preferential transfer of internalized PC to the endoplasmic reticulum.

\section{Acknowledgments}

This work was supported by National Institute of Health grants HL26710 and HL-19737.

\section{References}

1. Goerke, J. 1974. Lung surfactant. Biochim. Biophys. Acta. 344: 241-261.

2. King, R. J. 1979. Utilization of alveolar epithelial type II cells for the study of pulmonary surfactant. Fed. Proc. 38:2637-2643.

3. King, R. J., and H. Martin. 1980. Intracellular metabolism of the apoproteins of pulmonary surfactant in rat lung. J. Appl. Physiol: Respir. Environ. Exercise Physiol. 48:812-820.

4. Jobe, A., E. Kirkpatrick, and L. Gluck. 1978. Labelling of phospholipids in the surfactant and subcellular fractions of rabbit lung. $J$. Biol. Chem. 253:3810-3816.

5. King, R. J., and H. M. Martin. 1981. Effects of inhibiting protein synthesis on the secretion of surfactant by type II cells in primary culture. Biochim. Biophys. Acta. 663:289-301.

6. Brown, L. A. S., and W. J. Longmore. 1980. Adrenergic and cholinergic regulation of lung surfactant secretion in isolated perfused rat 
lung and in the alveolar type II cell in culture. J. Biol. Chem. 256:6672.

7. Dobbs, L. G., and R. J. Mason. 1979. Pulmonary alveolar type Il cells isolated from rats. Release of phosphatidylcholine in response to $\beta$-adrenergic stimulation. J. Clin. Invest. 63:378-387.

8. Desai, R., T. D. Tetley, C. G. Curtis, G. M. Powell, and R. J. Richards. 1978. Studies on fate of pulmonary surfactant in the lung. Biochem. J. 176:455-462.

9. Hallman, M., B. L. Epstein, and L. Gluck. 1981. Analysis of labeling and clearance of lung surfactant phospholipids in rabbit. Evidence of bidirectional surfactant flux between lamellar bodies and alveolar lavage. J. Clin. Invest. 68:742-751.

10. Jacobs, H., A. Jobe, M. Ikegami, and D. Conaway. 1983. The significance of reutilization of surfactant phosphatidylcholine. J. Biol. Chem. 258:4159-4165.

11. Fisher, A. B., C. Dodia, and A. Chander. 1985. Beta-adrenergic mediators increase pulmonary retention of instilled phospholipids. $J$. Appl. Physiol. 59:743-748.

12. Jacobs, H., A. Jobe, M. Ikegami, D. Miller, and S. Jones. 1984. Reutilization of phosphatidylcholine analogues by the pulmonary surfactant system. The lack of specificity. Biochim. Biophys. Acta. 793:300309.

13. Chander, A., W. D. Claypool, Jr., J. F. Strauss III, and A. B. Fisher. 1983. Uptake of liposomal phosphatidylcholine by granular pneumocytes in primary culture. Am. J. Physiol. 245(Cell Physiol. 14): C397-C404.

14. Bligh, E. G., and W. J. Dyer. 1959. A rapid method of total lipid extraction and purification. Can. J. Biochem. Physiol. 37:911-917.

15. Fisher, A. B., L. Furia, and H. Berman. 1980. Metabolism of rat granular pneumocytes isolated in primary culture. J. Appl. Physiol. 49: 743-750.

16. Chander, A., C. R. Dodia, J. Gil, and A. B. Fisher. 1983. Isolation of lamellar bodies from rat granular pneumocytes in primary culture. Biochim. Biophys. Acta. 753:119-129.

17. Jobe, A. 1977. The labeling and biological half-life of phosphatidylcholine in subcellular fractions of rabbit lung. Biochim. Biophys. Acta. 489:440-453.

18. Chander, A., J. Reicherter, and A. B. Fisher. 1984. Stimulation of phosphatidylcholine (PC) synthesis by fatty acids in rat granular pneumocytes in primary culture. Fed. Proc. 43:1655. (Abstr.)
19. Chander, A., A. B. Fisher, and J. F. Strauss III. 1982. Role of an acidic compartment in synthesis of disaturated phosphatidylcholine by rat granular pneumocytes. Biochem. J. 208:651-658.

20. Mitnick, M. A., B. Demarco, and J. M. Gibbons. 1980. Amniotic fluid phosphatidylglycerol and phosphatidyl inositol separated by stepwise-development thin layer chromatography. Clin. Chem. 26:277-281.

21. Mason, R. J., J. Nellenbogen, and J. A. Clements. 1976. Isolation of disaturated phosphatidylcholine with osmium tetroxide. J. Lipid Res. 17:281-284.

22. Yavin, E. 1967. Regulation of phospholipid metabolism in differentiating cells from rat brain cerebral hemispheres in culture. Patterns of acetylcholine, phosphocholine, and choline phosphoglycerides labelling from [methyl $\left.-{ }^{14} \mathrm{C}\right]$-choline. J. Biol. Chem. 251:1392-1397.

23. Robinson, B. S., A. M. Snoswell, W. B. Rucciman, and R. N. Upton. 1984. Uptake and output of various forms of choline by organs of the conscious chronically catheterized sheep. Biochem. J. 217:399408.

24. Bradford, M. M. 1976. A rapid and sensitive method for quantitation of microgram quantities of proteins utilizing the principle of protein dye binding. Anal. Biochem. 72:248-254.

25. Croxton, F. E. 1953. Elementary Statistics. Dover Publications Inc., New York. 109-143, 209-242.

26. Spitzer, H. L., J. R. Norman, and K. Morrison. 1969. In vivo studies of $\left[\mathrm{Me}-{ }^{3} \mathrm{H}\right]$ choline and $\left[1-2-{ }^{14} \mathrm{C}_{2}\right]$ choline incorporation into lung and liver lecithins. Biochem. Biophys. Acta. 176:584-590.

27. Nagley, P., and T. Hallinan. 1968. The use of radioactive choline as a label for microsomal membranes. I. Selectivity of label for endoplasmic reticulum and specificity for lecithin. Biochim. Biophys. Acta. 163:218-225.

28. DeDuve, C., T. DeBarsy, B. Poole, A. Trouet, P. Tulkens, and F. VanHoof. 1974. Commentary. Lysosomotropic agents. Biochem. Pharmacol. 23:2495-2531.

29. Sleight, R. G., and R. Pagano. 1984. Transport of a fluorescent phosphatidylcholine analog from the plasma membrane to the Golgi apparatus. J. Cell Biol. 99:742-751.

30. Infante, J. P. 1985. Impaired glycerophosphorylcholine synthesis in murine muscular dystrophy. Med. Biol. 63:81-87.

31. Sarzala, M. G., and L. M. VanGolde. 1976. Selective utilization of endogenous unsaturated phosphatidyl-cholines and diacylglycerols by choline phosphotransferase of mouse lung microsomes. Biochim. Biophys. Acta. 441:423-432. 